\title{
INVESTIGATION OF STRONG COLUMN - WEAK BEAM RATIO IN MULTI-STOREY STRUCTURES
}

\author{
Hande GÖKDEMİR ${ }^{1, *}$, Ayten GÜNAYDIN ${ }^{1}$ \\ ${ }^{1}$ Eskişehir Osmangazi University, Department of Civil Engineering, Eskişehir, Turkey
}

\begin{abstract}
It is expected that the engineering constructions should carry the vertical and horizontal loads during the service within the determined safety margin. The basic principal of having strong column-weak beam preference is essential for earthquake resistant structures for all construction types including concrete, steel, wood and prefabricated. The major criteria for having earthquake resistant structure is to ensure that the columns are stronger and carry the most load than the beam in the nodes. This criterion has been widely adopted in earthquake codes in Europe, USA, Japan and India. It is possible to absorb and consume the earthquake energy via beam plastic joint hinges if the columns are constructed to be more durable than the beams. For this, it is foreseen that the ratio of the ultimate strength of the upper and lower columns to the right and left beams $(\beta)$ should be greater than one $(\beta=1.2)$ in the beam-column joints as stated in the Turkish Earthquake Code. This coefficient is usually greater than 1.2 in the earthquake codes adopted in the world. It was observed that many structures were damaged or collapsed due to not meeting the coefficient criteria stated above. This criterion is the most effective one among many to prevent the damage in the structure under seismic action. In this study, the effect of the change in the coefficient on the column and beam moments is investigated under the Turkish Earthquake Code. Different numerical examples are presents for the coefficient of 10. The results of the investigation highlighted that irregularity in the strong column-weak beam composition may negatively affect the other irregularities in the structure.
\end{abstract}

Keywords: Strong column-weak beam, Beam-column joint, Plastic hinge, Ultimate strength

\section{INTRODUCTION}

The design of the structures is made according to horizontal and vertical loads. Structures are allowed to be damaged at certain rates under the influence of these loads. In a destructive earthquake, it is expected that the structure to have some damage but enable the safety of living in the structure. Structures that are not properly designed for seismic loads may have destructive consequences. Structures are also be destructed or collapsed due to economic or functional purposes due to changes in expected service characteristics over time. For these reasons, it is the most appropriate solution to design the structure by taking basic structural precautions such as appropriate material characteristics, restricting the irregularities and improving performance. Joints which is the column beam joints forming the most critical region in the structure are critical in addition to the individual strength of the basic elements in this regard (Figure 1). This is simply because it is not easy to make beams and columns work together under seismic loads, where beam carry more bending effect and columns carry more vertical loads. Since the strength of the node is more effective than the strength of the systems in order to carry the seismic loads, the criteria are carefully controlled by the regulation. One of this critical point is to ensure that the ultimate strength of columns are greater than the beams at the joint. 


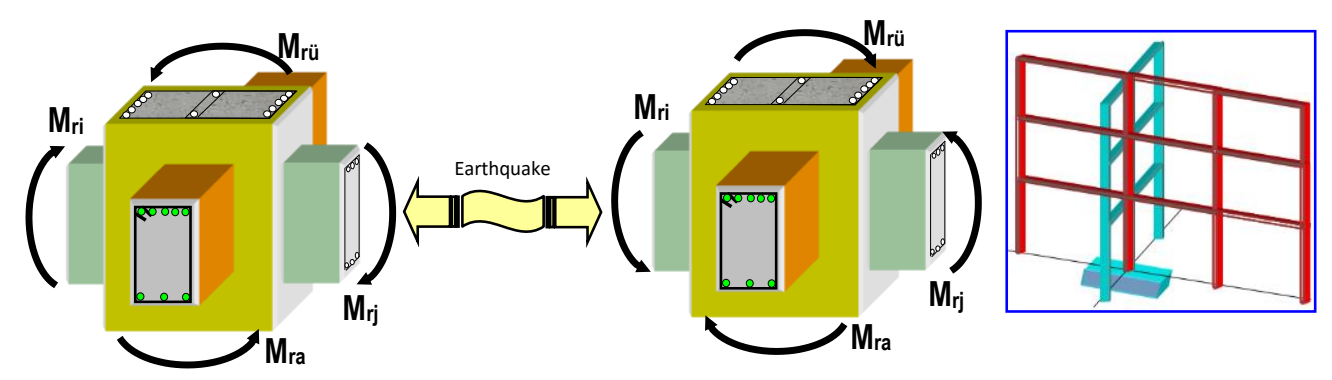

Figure 1. The ultimate limit state moments in beam-column joints

2007 Turkish Earthquake Code (TEC) presents the strong column-weak beam criterion as follows [1].

$$
\left(M_{r a}+M_{r i ̈}\right)_{\text {column }} \geq 1.2\left(M_{r i}+M_{r j}\right)_{\text {beam }}
$$

According to this criterion, it is expected that the sum of the bearing moments of the columns should be at least $20 \%$ greater than the bearing moments of the beams at the joint, where $\mathrm{M}_{\mathrm{r}}$ is calculated based on the $\mathrm{f}_{\mathrm{cd}}$ concrete and $\mathrm{f}_{\mathrm{yd}}$ steel bars ultimate strength [1]. This $20 \%$ in TEC criterion has been set $20 \%$ in ACI 318 [2], 30\% in Eurocode-8 [3], and 40\% in India Earthquake Codes [4]. The column-beam joints of multi-storey structures are illustrated in Figure 2. In this illustration, all combinations except 2a present a brittle behaviour due to insufficient energy absorbing capacity (Figs. 2b-c-d). This type of behaviour is not desirable under seismic loads. This criterion is not controlled in the last storey of a structure or columns with low axial load $\left(\mathrm{N}_{\mathrm{d}} \leq 0.10 \cdot \mathrm{A}_{\mathrm{c}} \cdot \mathrm{f}_{\mathrm{ck}}\right)[1]$.

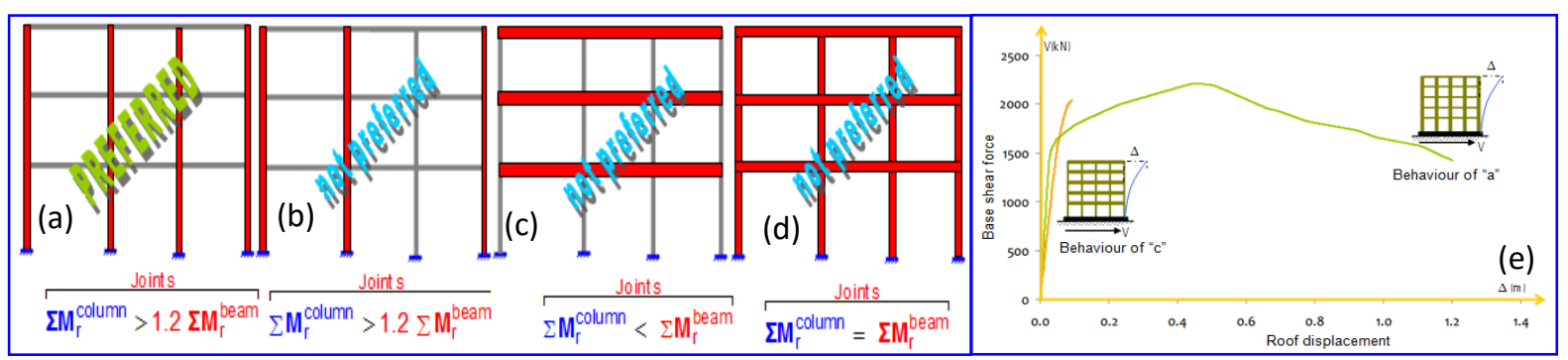

Figure 2. Column-beam joints in frame structure [5]

It is expected that the energy generated by the earthquake can be absorbed by the formation of the plastic hinges in the beams. In case the carrying forces of the columns are not equal to or higher than the beams, the energy generated by seismic loads will be consumed by the columns, resulting from the structural damage in the columns and possible collapse of the building (column and column-beam mechanism) (Figure 3). Because the beams have low axial load levels, and therefore they are more ductile and reach the plastic hinge points earlier than the columns.

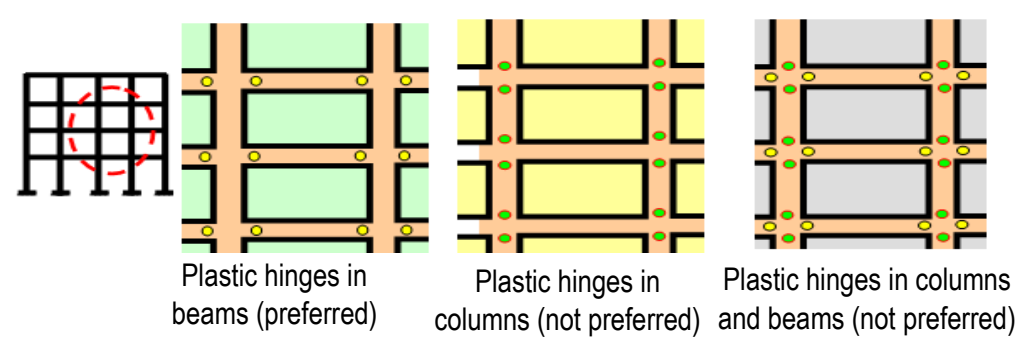

Figure 3. Collapse Mechanism [6] 
It is observed that the columns have significant structural damage if beams are designed to have higher ultimate strength than columns (Figure 4). Additionally, when there is no wall between columns, the bottom ends of the columns are severely damaged (B1 irregularities). This is due to the sudden section change in these regions, where storey slabs stay more rigid than columns, so the columns get damage under seismic loads.

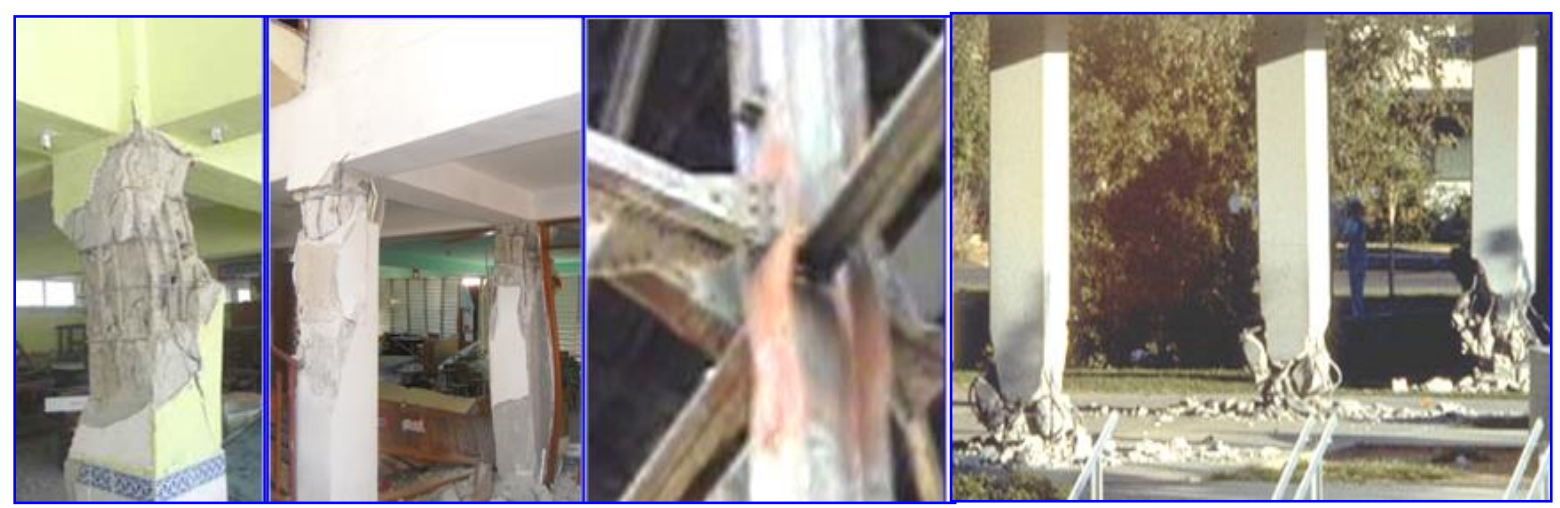

Figure 4. Weak column-strong beam failure [5]

TEC requires that structures with the structural importance coefficient (I) 1.4 and 1.5 should be designed to ensure the strong column-weak beam arrangements [1].

\subsection{TEC Applications of Having Columns Stronger than Beams}

The strong column-weak beam application is a very effective parameter for the design of the structure. Therefore, this approach is mentioned multiple sections of the TEC as listed below. The criterion is also seen as an effective parameter in strengthening existing structures.

\subsubsection{Requirement of Having Columns Stronger Than Beams}

3.3.5.1-In structural systems comprised of frames only or of the combination of frames and walls the sum of ultimate moment resistances of columns framing into a beam-column joint shall be at least $20 \%$ more than the sum of ultimate moment resistances of beams framing into the same joint (Fig. 3.4) 3.3.5.2 - In order that Equation (3.3) is applied, beams framing into the joint shall satisfy the dimensional requirements given in 3.4.1.1.

3.3.5.3 - Eq (3.3) shall be applied separately for both earthquake directions and senses to yield the most unfavorable result (Fig. 3.4). In calculating the column ultimate moment resistances, axial forces $\mathrm{Nd}$ shall be taken to yield the minimum moments consistent with the sense of earthquake direction.

3.3.5.4 - Special situations regarding the application of Equation (7.3) are described in the following:

(a) Equation (3.3) need not to be applied in the case where Nd 0.10 Ac fck in both columns framing into the joint.

(b) Equation (3.3) need not to be checked in single storey buildings and in joints of topmost storey of multi-storey buildings.

(c) Equation (3.3) need not to be checked in the case where a wall connected by beams works like a column in its weak direction. 


\section{LITERATURE REVIEW}

Tsonos [7] investigated the performance of column-beam joints under the seismic loads on a four $1 / 2$ scale test specimens. All elements are designed according to the weak beam-strong column criterion in accepted building codes. A large number of inelastic cycles were applied to the combinations. Higazy and at all have carried out experiments on the interior columns of a multi-storey structure to investigate if there is tensile effect occurs under seismic loads. This experiment was applied to 6 interior column beam joints on a specifically designed shake table. It is observed that deformation increases and shear strength is lost when the columns are subject to tensile and column pressure load decreases significantly [8]. In another study, Febres and Wight tested three internal, wide column-beam-slab combinations under semi-static cyclic loadings. They concluded that if large interior beam-column joints were designed properly, deformation capacity is increased and sufficient strength was obtained [9]. Murty also tested the $\beta$ ratio and suggested that $\beta=1.2$ is insufficient because it causes plastic joints to form in the columns (Figure 5a). Murty found out capacities of energy absorption and shear force are increasing with the higher $\beta$ ratio. However, larger $\beta$ ratios also makes the structure more rigid and the magnitude of the earthquake forces is large [10], which is another point should be considered. In this study (Figure 5a), Murty has determined that the ratio of $\beta$, the capacities of energy consumption and shear force are increasing. This is also a separate study of the fact that the magnitude of this ratio is also very rigid and the magnitude of the earthquake forces is large [10]. As the column beam stiffness ratio increases, the column moments increase (Figure 5b).

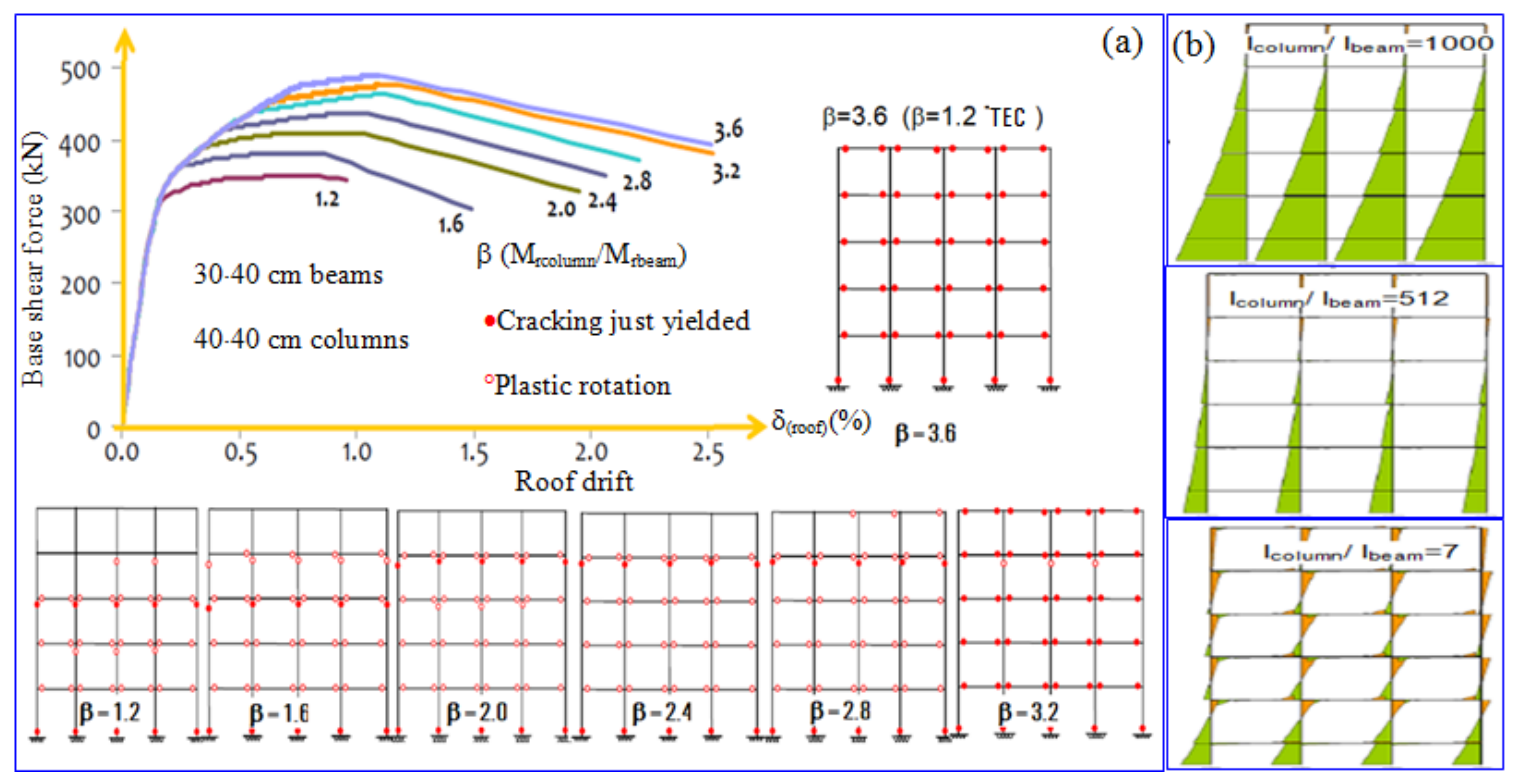

Figure 5. (a) Capacity curves and change of collapse mechanism to frame; (b) Ratio of moment of inertia column to beam

When the above figure is examined, the structural system reaches to the failure point with the $\beta$ value 3.6. In this study, since the ultimate strength values are not used, the $\beta$ is calculated by taking EI / L at beams and $\mathrm{EI} / \mathrm{h}$ at columns. The taking of 10 values of $\beta$ was made in order to make the comparison of the values of moment and displacement found in the solutions to be more prominent.

\subsection{Application of Strong Column-Weak Beam in Multi-Storey Structures}

Horizontal displacement distributions of multi-storey frames under earthquake loads are given below (Figure 6). In this figure, $h_{i}, \delta_{i}$ and $\Delta$ represent the storey heights, the relative storey displacements, and the top displacements of the structure respectively. 

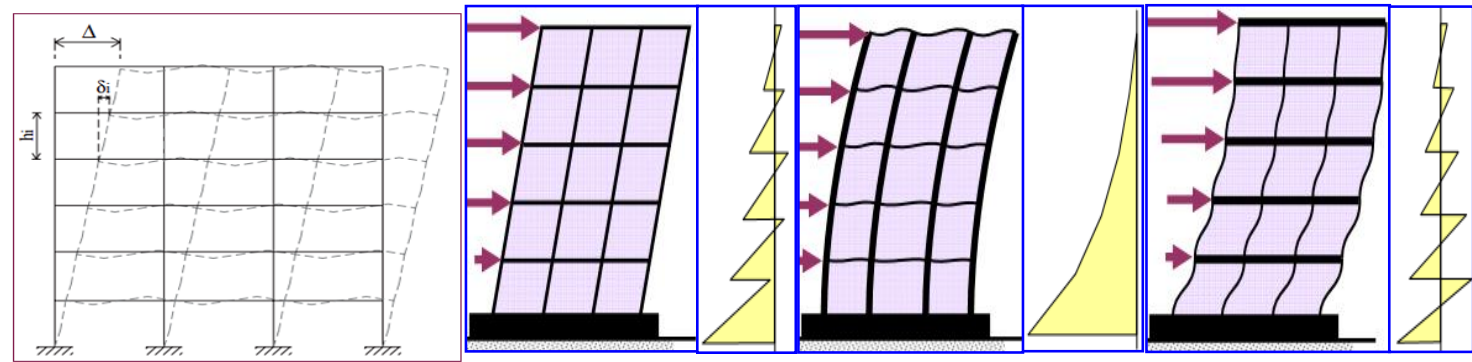

Figure 6. Displacements of frame structure

Elnashai and Sarno studied behaviour of the strong column-weak beam (SCWB) and strong beam-weak column (WCSB) frames under horizontal loads. As shown in Figure 7, in the case of SCWB, the storey displacements are lower than the WCSB condition.
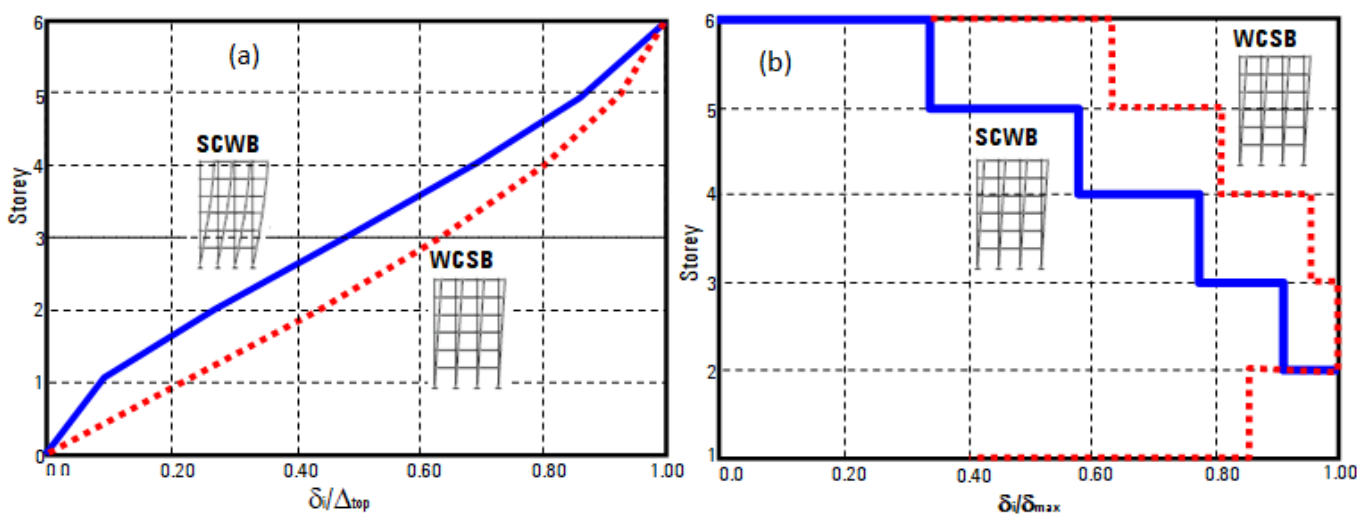

Figure 7. Storey displacements of SCWB and WCSB conditions

In the case shown in Figure $7 \mathrm{a}$, the ratio of the relative storey displacements to the top storey displacement $\left(\delta_{\mathrm{i}} / \Delta\right)$ is given for each storey in the horizontal axis for the SCWB and WCSB cases. In addition, Figure $7 \mathrm{~b}$ shows the ratio of the relative storey displacements to the largest relative storey displacement $\left(\delta_{\mathrm{i}} / \delta_{\max }\right)$ for these two cases. It is obvious that SCWB storey displacements are lower than WCSB storey displacements. In addition, in Figure $7 \mathrm{~b}$, the greatest $\left(\delta_{\mathrm{i}} / \delta_{\max }\right)$ ratio is observed in the 2nd storey for the SCWB case, and in the 3rd storey for the WCSB case. Furthermore, Figure 8 presents the comparison of the storey displacements of two frames, where the column and beam sections consistent in one case and the column and beam sections present irregularity in the second storey in another case. Hence, the relative second storey displacements give significantly higher displacements compared to other storeys (Figure 8) [11].
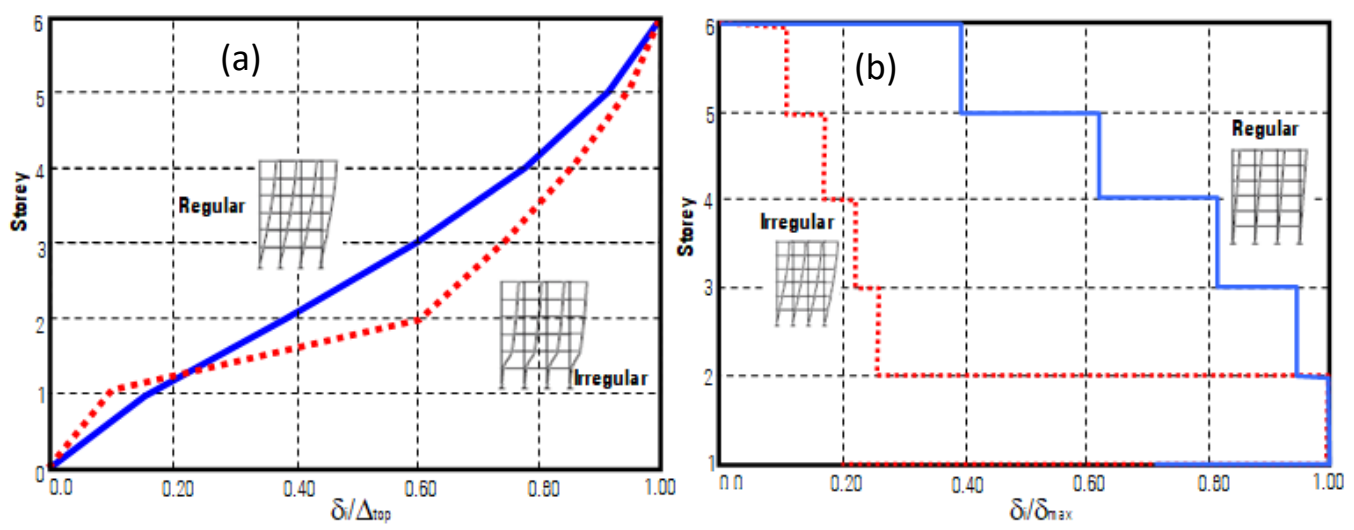

Figure 8. Relative storey displacement of regular and irregular frame structures 
One of the basic principles of the earthquake codes is to enable the formation of the plastic hinges on the beams during the seismic loads, so that they can absorb more energy. This behaviour will prevent sudden collapse by minimizing the local and complete failures. This approach seems to be possible only if the columns behave stronger than the beams. This can also be used as a precaution against some structural irregularities. For example, in the case of $\mathrm{B} 2$ type irregularities, Eurocode8 uses $\mathrm{M}_{\mathrm{r} \text {,column }}>1.3 \mathrm{M}_{\mathrm{r} \text {,beam }}$ criteria to reduce the effect of the irregularity in the system [3]. Earthquakes create dynamic loads at different amplitudes that can cause deformation in different directions, exceeding the elastic threshold of structures. Load direction changes can cause stiffness reduction and the vibration period leads to shifting to the inelastic range. According to an extensive study conducted by Mwafy and Elnashai [12] on the seismic response of reinforced concrete structures indicates that the structural expansion of the inelasticity leads to a loss of stiffness, which causes remarkable prolongation of the vibration period.

\section{PROPOSED SOLUTION}

A four-storey frame with $4 \mathrm{~m}$ beam spans and $3 \mathrm{~m}$ storey heights were studied with SAP2000 [13] package program. The Bernoulli hypothesis, Hooke's material, first order theory and superposition rules are applied in analyses. Horizontal loads are calculated according to equivalent static load method. The dead and live loads were considered $\mathrm{G}=20 \mathrm{kN} / \mathrm{m}$ and $\mathrm{Q}=15 \mathrm{kN} / \mathrm{m}$ respectively (Figure 9).

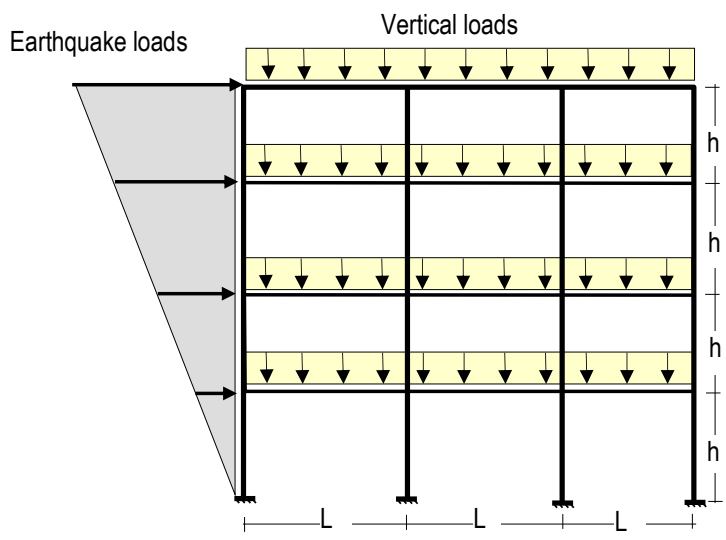

Figure 9. Frame structures under earthquake and vertical loads

The solution of the frame is calculated for three loading cases, vertical, horizontal and both vertical and horizontal, for the cases $[E I / h]_{\text {column }}>10[E I / L]_{\text {beam }}$ and $[E I / h]_{\text {column }}<10[E I / L]_{\text {beam }}$, and the results are compared. The moment values of the interior and exterior columns and beams are given in the figure and the moment values at the first and top storeys are compared for the mid-span and edgespan beams (Figure 10).
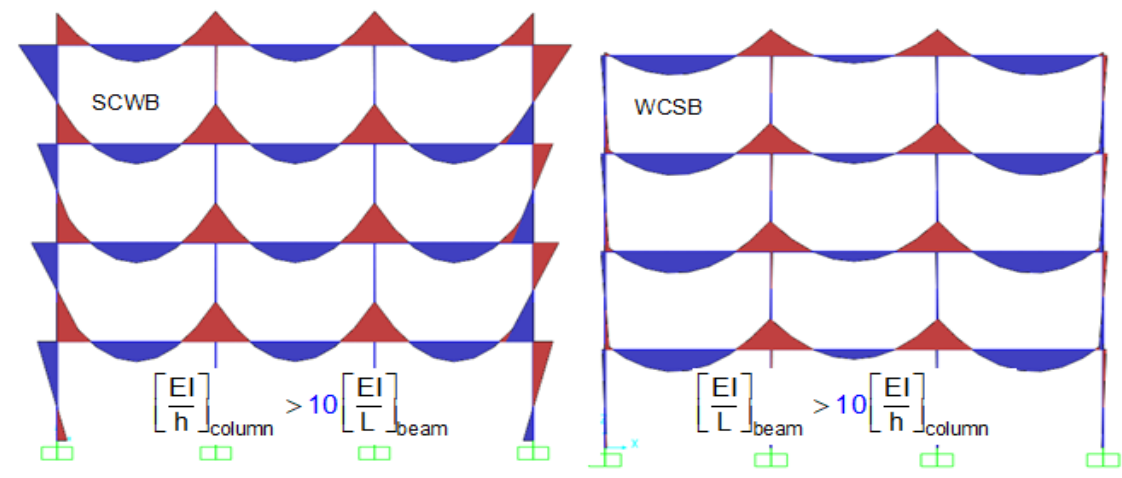

Figure 10. Moment diagram of the column and beams under the vertical loads 
Results of the comparative analyses indicate that when the columns are stronger than the beams under the vertical loads. It is seen that the moment values decrease from the lower storeys to the upper storeys (Table 1). In the case of WCSB, the moments in the edge-span beams are less in the centre and higher close to the joints compared to SCWB case. On the other hand, in the mid-span beams, the moment values are close to each other in both cases. If the columns are weaker than the beams, the column moments are quite small. In these calculations, the additional moments due to the shear effects and the length change are ignored.

Table 1. Beam moment values under vertical loads $(\mathrm{kNm})$

\begin{tabular}{|c|c|}
\hline $1.5 t$ & $1 \mathrm{~m} 2 \mathrm{~m} 3 \mathrm{~m} 4 \mathrm{~m}$ \\
\hline \multirow{2}{*}{\multicolumn{2}{|c|}{$\begin{array}{l}\text { CWB edge-span-39.19 } 5.5120 .214 .90-40.40 \\
\text { NCSB edge-span -8.19 26.9132.01 } 7.11-47.78\end{array}$}} \\
\hline & \\
\hline \multicolumn{2}{|c|}{ SCWB mid-span -40.00 5.00 20.00 5.00-40.00 } \\
\hline \multicolumn{2}{|c|}{ WCSB mid-span -45.41-0.41 14.59-0.41-45.41 } \\
\hline 4. $S$ & $1 \mathrm{~m} 2 \mathrm{~m} 3 \mathrm{~m} 4 \mathrm{~m}$ \\
\hline \multicolumn{2}{|c|}{$\begin{array}{l}\text { SCWB edge-span-31.99 } 5.01 \quad 17.014 .02-33.98 \\
\text { NCSB edge-span -4.60 24.0727.75 6.42 }-39.90\end{array}$} \\
\hline \multicolumn{2}{|c|}{ SCWB mid-span -33.35 $4.1516 .654 .15-33.35$} \\
\hline WCSB mid-s & 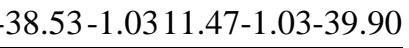 \\
\hline
\end{tabular}

Displacement and beam moment values under vertical loads are calculated as follows:
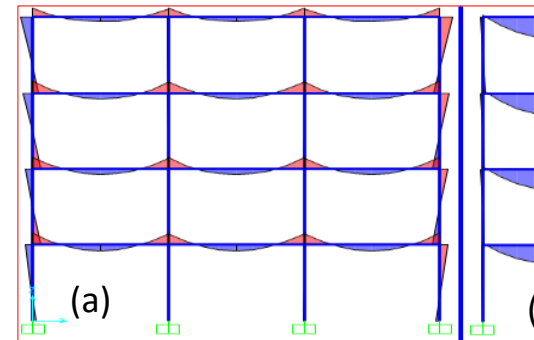

(c)
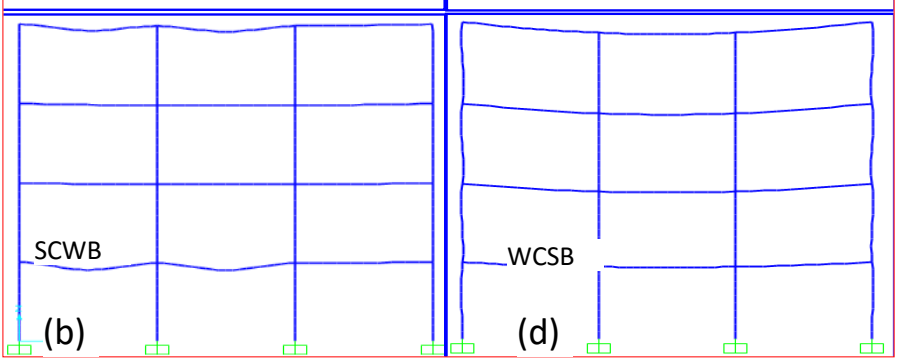

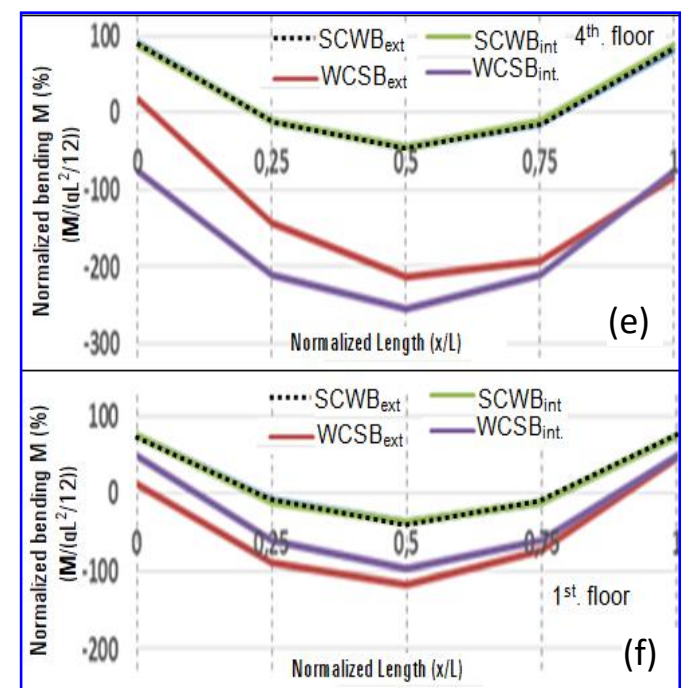

Figure 11. a-c: Distribution of bending moments in SCWB and WCSB multi-storey frames under vertical loads b-d: Displacements of frame e-f: Normalized bending moment versus normalized length

Figures 11a-c shows moment values for SCWB and WCSB cases, Figure 11b-d shows displacement forms of the frames, and Figures 11e-f shows moment changes of 1st and 4th storey beams respectively. Figures 11e-f shows normalized (non-dimensional) moment values for the ratio of $0,0.25,0.50,0.75$ and 1 of the beam width. For example, for the top storey and the WCSB case, the moment value of the mid-span beam is about 5 times smaller than the value in the same place for the mid-span beam for SCWB.

In the case where there are only vertical loads, to frame system is subject to the least force for the displacements. Because the axial load of reinforced concrete columns and the bending capacities of beams are considerably higher than the displacements occurs under seismic loads. 


\section{SCWB case,}

1. Column moments are larger in WCSB case and smaller in SCWB case due to their large stiffness,

2. The beam span moments are small and the change between the storeys is presented on the graph,

3. In the interior joints, moment values are larger close to the joints,

4. The moment values of inner columns are considerably smaller than those of outer columns.

\section{WCSB case,}

1. The vertical displacement of the frame increases towards the upper storeys and becomes larger in the middle columns,

2. The displacements of the beams are small in the edges and large in the middle due to the columns,

3. As the beam span moments increase towards the upper storeys, the support moments decrease,

4. The support moments are very small in the edge-span beams.

It is possible to increase these comparison criteria.

The following Figure 12 presents the moment values, displacement and beam moment values under the horizontal loads only.

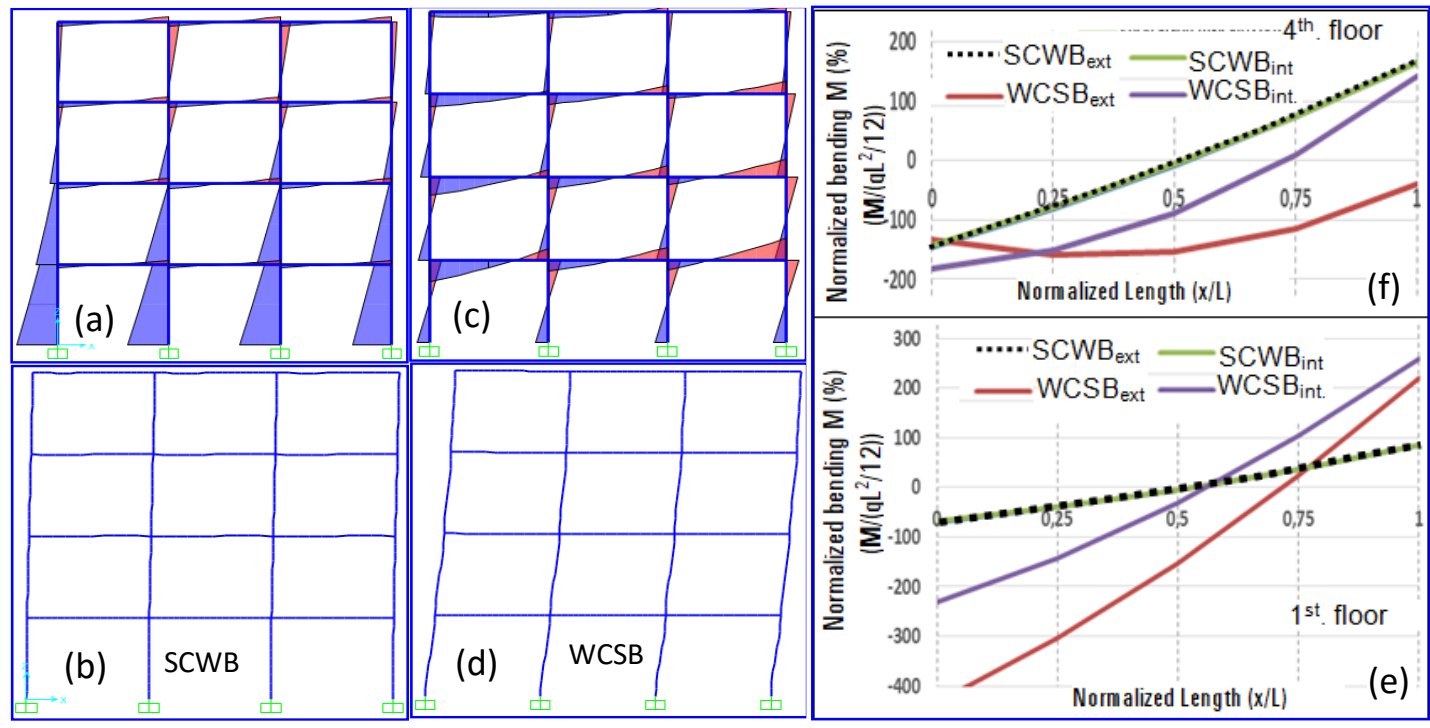

Figure 12. a-c: Distribution of bending moments in SCWB and WCSB multi-storey frames under horizontal loads b-d: Displacements of frame e-f:Normalized bending moment versus normalized length

Figures 12a-c presents the moment values for SCWB and WCSB cases, Figure 12b-d presents the displacement, and Figures 12e-f presents the beam moment variations of 1st and 4th storey beams, respectively. Figures $12 \mathrm{e}-\mathrm{f}$ presents normalized (non-dimensional) moment values for the ratio of 0 , $0.25,0.50,0.75$ and 1 of the beam span.

\section{SCWB case,}

1. Column moments decrease from bottom to top storey due to the large stiffness,

2. While the beam moments do not show much change in the span, they show large changes close to the joints,

3. Horizontal displacement of the frame stay relatively small compared to the WCSB case,

4. It is observed that the moments of the middle columns change sign especially when going from the bottom storeys to the top storeys. 


\section{WCSB case,}

1. Beam support moments are smaller at the loading points compared to the far ends and decrease as they go to the upper storeys,

2. The beam moment values at the loading points decrease towards the upper storeys,

3. Column moments are larger in the outer columns than in the interior columns and decrease towards the upper storeys.

The following Figure 13 presents the condition for the combined effect of vertical loads and seismic loads:

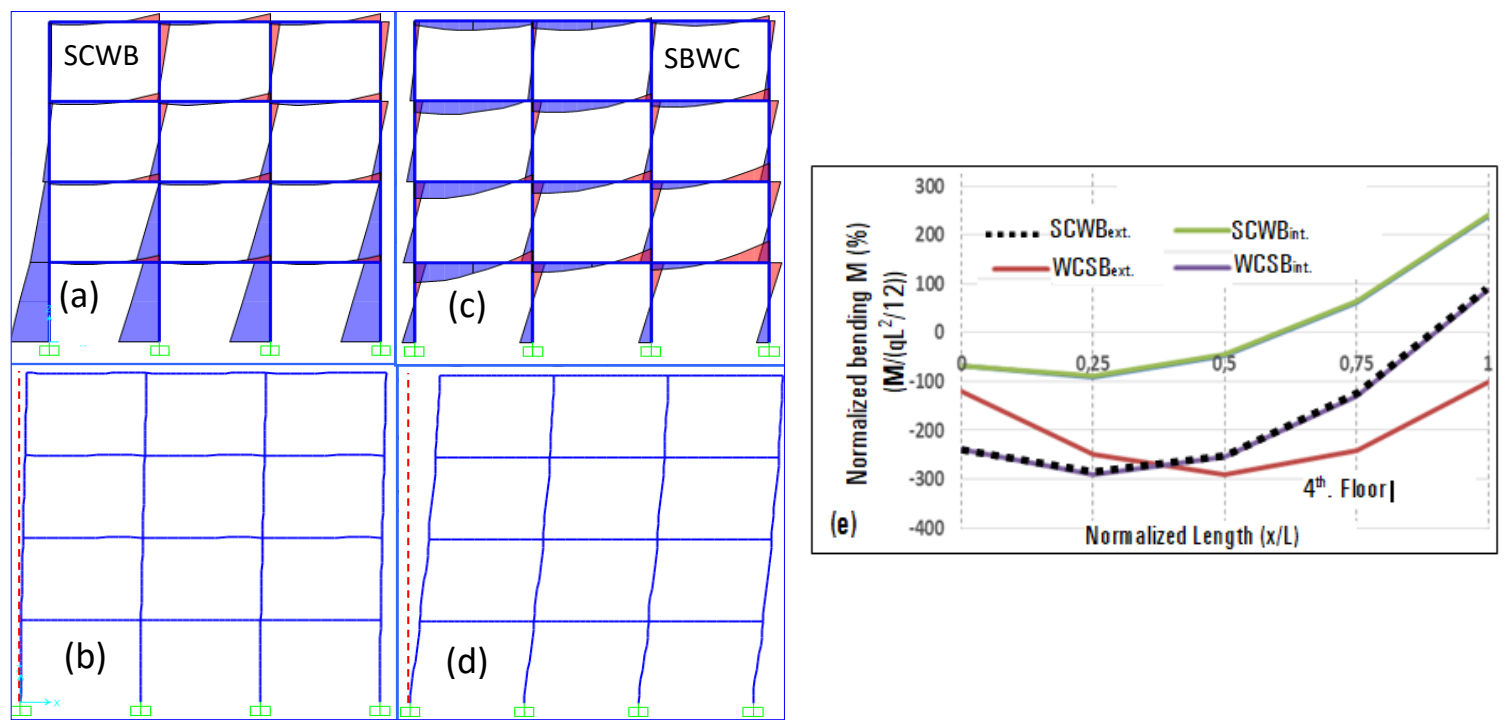

Figure 13. a-c: Distribution of bending moments in SCWB and WCSB multi-storey frames under vertical and horizontal loads b-d: Displacements of frame e: Normalized bending moment versus normalized length

Figure 13 above presents the case where the horizontal loads and the vertical loads act together.

Figure 13a shows the moment values, Figure 13b shows the displacement of the structure and Figure $13 \mathrm{e}$ shows the moment change in the fourth storey beam. It is seen that when the columns are strong, the beam support moments decrease from the lower storeys to the upper storeys. Additionally, in the case of weak columns, it is seen that the change in the medium supports is rather small, especially when the edge bearing moments have very small values.

1. The beam moments for the WCSB case are larger than the beam moments for the SCWB case,

2. The column moments for the WCSB case are larger than column moments for the SCWB case,

3. For the WCSB case, the beam support moments decrease from the lower storeys to the upper storeys.

The presence of only horizontal loads in the frames is a loading condition that forces the system to make deformation more than the vertical loading conditions. Because axial load capacities of reinforced concrete columns and bending capacities of beams are not fully used under these horizontal loads. The columns are designed as vertical load bearing elements and the displacement is increased due to the weak horizontal stiffness under horizontal loadings. The main problem in all structural systems is that the horizontal loads have been carried by vertical elements and continue to exist. If the horizontal loads are carried by the horizontal elements and vertical loads are carried by the vertical elements, the problem becomes much simpler because they will be subject to the axial load as similar to truss systems. 


\section{RESULTS AND DISCUSSION}

From the analysis, in the case where columns are stronger than the beams (SCWB);

- In particular, horizontal displacements are very small under seismic loads,

- The column moments decrease from the lower storeys towards the upper storeys,

- Change of the beam support moments increase from the upper storeys to the lower storeys,

- The beam span moments decrease towards the upper storeys under the vertical loads only,

- Moment changes are same due to symmetry in the edge-span and mid-span beams,

In the frames where the beams are stronger than the columns (WCSB),

- The support moments are large at the beam where horizontal loads are applied, and gets smaller as moves forward,

- Beam support moments decrease towards the upper storeys,

- It is seen that the span moments increase towards the upper storeys under the vertical loads only.

The $\beta$ ratio has a positive correlation with aforementioned changes, as the $\beta$ ratio increase changes increase and $\beta$ ratio decrease changes decrease. It is beneficial to make a more detailed analysis of the ratio given in TEC. The strength of the columns is not in the sense that the beams are weak, and it is obvious that the structures should sufficiently be strong in the beams to provide earthquake resistance.

From the analysis under of seismic loads, the horizontal displacements of SCWB frames are quite low compared to WCSB frames under the same loads, which also prevents B2 type irregularities in TEC. Also in the structures, if $\beta \geq 2$, that is to say the frames are dimensioned as SCWB, gives a high level of ductility. This suggests that the earthquake load reduction coefficient $R_{a} \geq 5-8$ is taken in TEC. In other words, if the frames are SCWB, the ductility level is high and the earthquake load is divided by 5-8, while WCSB is considered, the earthquake load can be split 2-4 by assuming the ductility level as normal. The design seismic load can be reduced by $50 \%$ by increasing the ductility level in the structure. This discussion can continue in the cases where structure includes structural walls, prefabricated and columns are $20 \%$ stronger than the beams as stated in TEC.

\section{REFERENCES}

[1] TEC. Deprem Bölgelerinde Yapılacak Binalar Hakkında Yönetmelik. Bayındırlık ve İskan Bakanlığı (in Turkish), Ankara, 2007.

[2] ACI Committee 318. Building Code Requirements for Structural Concrete. American Concrete Institute, Detroit, MI, 2002.

[3] EC8. Design Provisions for Earthquake Resistance of Structures. Pub. ENV-2003-2, Comite Europeaen 23 de Normalization, Brussels, 2003.

[4] IS:1893 (Part 1). Indian Standard Criteria for Earthquake Resistant Design of Structures, Bureau of Indian Standards, New Delhi, 2007.

[5] Doğan M. Yapıların Deprem Analizi, Eskişehir Osmangazi Üniversitesi, Yayın No:143, ISBN 978975-7936-52-7 (in Turkish), 2012.

[6] FEMA 356. NEHRP Commentary on the Guidelines for the Seismic Rehabilitation of Buildings. FEMA 356, Washington, DC., USA, (2000). 
Gökdemir and Günaydın / Anadolu Univ. J. of Sci. and Technology A-Appl. Sci. And Eng. 19 (2) - 2018

[7] Tsonos AG. Cyclic load behaviour of reinforced concrete beam-column sub assemblages of modern structures. ACI Struct J 2007; 104(4): 468-478.

[8] Higazy M, Elnashai S, Agbabian S. Behaviour of beam-column connections under axial column tension. J Struct Eng 1996; 122 (5): 501-511.

[9] Febres C, Wight J. Experimental study of reinforced concrete interior wide beam-column connections subjected to lateral loading. ACI Struct J 2001; 98: 572-582.

[10] Murty CVR. IITK-BMTPC Earthquake Tips-Learning Earthquake Design and Construction, National Information Centre of Earthquake Engineering, NICEE, India: 2005.

[11] Elnashai AS, Sarno LD. Fundamentals of Earthquake Engineering. 1st ed. New York, NY, USA: Wiley, 2008.

[12] Mwafy AM, Elnashai AS. Static pushover versus dynamic collapse analysis of RC buildings. Eng Struct 2001; 23(5): 407-424.

[13] SAP2000. Structural Analysis Program. CSI, Berkeley, USA. 